\title{
PRINCIPIOS GENERALES DE LOS CONTRATOS ADMINISTRATIVOS: LA LEY 13/1995, DE 18 DE MAYO ${ }^{1}$
}

\author{
José Luis Avila Orive \\ Profesor Titular de Derecho Administrativo \\ Universidad de Deusto
}

Sumario: 1. Consideraciones generales. 2. Principios básicos: A) La configuración sustantiva del contrato administrativo. B) Publicidad y concurrencia. C) Igualdad y no discriminación. D) Riesgo y ventura. E) Equivalente económico. F) Supremacía de la Administración. G) Contractus lex. H) La forma del contrato.

\section{Consideraciones generales}

Reflexionar sobre la actividad contractual de las Administraciones públicas supone abordar, como es sabido, una materia administrativa singular, por cuanto las manifestaciones productoras de efectos jurídicos, no provienen de las declaraciones unilaterales de las Administraciones públicas, sino del acuerdo de voluntades pertenecientes a otros sujetos además de la correspondiente a la Administración.

La aplicación de la institución privada a las relaciones contractuales de las Administraciones públicas no ha supuesto en nuestro ordenamiento jurídico una alteración de la posición privilegiada de las Administraciones públicas, sino más bien la asimilación y adaptación de la figura privada del contrato a los parámetros de funcionamiento del derecho administrativo.

Sin embargo, no parece de utilidad a estas alturas, revolver en la polémica doctrinal, acerca de la conveniencia del ordenamiento jurídico-administrativo o del ordenamiento privado como ordenación jurídica más adecuada para las relaciones contractuales de las Administraciones públicas.

1 Corresponde a la Conferencia desarrollada en las Jornadas sobre la citada Ley, organizadas por el Colegio de Secretarios, Tesoreros e Interventores de la Administración Local de Bizkaia. 
La consolidación del Derecho administrativo, llevada a cabo por la Ley de Contratos del Estado de 8 de abril de 1965 (LCE), como ordenamiento regulador de los contratos celebrados por las Administraciones públicas ligados al desenvolvimiento regular de un servicio público o portadores de especiales características que supongan la tutela del interés público, además de todos aquellos tipificados legalmente, aconseja más bien el análisis de los principios estructuradores del ordenamiento jurídico aplicable a los contratos administrativos, desde la aceptación de la presencia de intereses públicos y la correspondiente posición privilegiada de la Administración, y la pretensión de alcanzar un adecuado equilibrio entre las partes².

La reforma operada con la Ley 13/1995, de 18 de mayo, no ha supuesto la incorporación de principios ignorados o desconocidos en la legislación anterior, salvo por lo referido a la necesaria extensión provocada por el derecho comunitario ${ }^{3}$, sino más bien la más completa aplicación y definición de algunos de los mismos.

En ese sentido, los principios comunitarios de publicidad de los contratos públicos que se celebren en la Unión Europea y superen la correspondiente cantidad de Ecus, de no discriminación de empresarios no nacionales, de libre concurrencia y de garantía de los derechos reconocidos a los contratistas por el derecho europeo ${ }^{4}$, se incorporan íntegramente al esquema principial que explica y estructura la nueva Ley.

Asimismo, buena parte de la reforma es sensible a la detección y la consiguiente corrección de una serie de problemas largamente puestos de

2 Lo que GASPAR ARIÑo viene a señalar, en La reforma de la Ley de Contratos del Estado, Unión Editorial, p. 98, como el esfuerzo por reconstruir la «igualdad en que todo contrato consiste» y perfeccionar los mecanismos de garantía que compensan los privilegios.

3 Es preciso tener en cuenta los principios originarios de libertad de circulación de mercancías, libertad de establecimiento y principio de no discriminación, contenidos en el Tratado constitutivo de la Comunidad europea de 1957, además del conjunto de Directivas referidas a la contratación que constituyen referencia obligada: La Directiva 93/36/CEE, sobre contratos de suministro; 93/37/CEE, sobre contratos de obras; 93/38/CEE sobre contratos en los denominados «sectores excluidos», es decir, agua, energía, transportes y telecomunicaciones; 92/50/CEE, sobre contratos de servicios públicos; 89/665/CEE y 92/13/CEE sobre las garantías de los contratistas y régimen de recursos, materia sobre la que no se ha producido adaptación en la LCAP, porque nuestra legislación en materia procesal y procedimental ya recoge sus determinaciones.

Además se tienen en cuenta los aspectos derivados del Acuerdo sobre el Espacio Económico Europeo y del Acuerdo sobre Contratación Pública de la Organización Mundial del Comercio.

4 Vid. Cosculluela Montaner, L.: Manual de Derecho Administrativo, Cívitas, 6. ${ }^{\mathrm{a}}$ ed., 1995, pp. 390 y ss. OJeda MARín, A.: «Contratos públicos en la Comunidad Europea: La Ley de Contratos del Estado y su adecuación al ordenamiento jurídico comunitario», RAP, núm. 112, pp. 147 y ss. 
manifiesto, que no siempre están relacionados con carencias atribuibles al ordenamiento, sino a deficiencias en su gestión.

El diseño de procedimientos adecuados de selección de contratistas, que tengan en cuenta no sólo la oferta sino quién la realiza, la determinación de procedimientos rápidos de ejecución de los contratos, el establecimiento del equilibrio en las prestaciones recíprocas, el aseguramiento del justo precio del contrato, la correcta ordenación temporal del gasto público y su correspondiente ejecución, la diligente tramitación de expedientes o la certera elaboración, en su caso, de los proyectos de inversión, son manifestaciones de una y otra clase.

Por tanto, la reforma que se va a analizar obedece a esos problemas, pero también como se ha dicho y es sabido, a la necesaria adaptación de la legislación española al derecho comunitario, que completa la insuficiente y contestada, por la Comisión europea, adaptación realizada por el Real Decreto Legislativo 93/1986, de 2 de mayo, y también, por qué no decirlo, al compromiso político asumido de establecer medidas eficaces contra la corrupción ${ }^{5}$.

Hay que considerar en primer lugar, como antes se ha adelantado, que la consolidación definitiva del contrato administrativo que llevó a cabo la Ley y Reglamento de contratos del Estado es un elemento básico sobre el que reposa esta nueva Ley promulgada treinta años después, y que resulta básico para entender adecuadamente el sentido y objetivos de la Ley y consecuentemente la posición de las Administraciones públicas en la inteligencia, desarrollo y ejecución de los contratos administrativos.

Efectivamente la naturaleza administrativa y la correspondiente disposición de un derecho público de la contratación, implica la existencia de una serie de prerrogativas y privilegios administrativos, en cuanto instrumentos que se justifican por la presencia del interés público, pero también implica la existencia del principio de igualdad ante las cargas públicas y, en esa medida, el aseguramiento del equivalente económico en las contraprestaciones contractuales o justo precio, cuya justicia no proviene del acuerdo, «tantum valet res quantum vendi potest», sino del exquisito equilibrio entre prestaciones y precio. Implica también publicidad y libertad de concurrencia y por tanto imposibilidad de contratar con quien libremente se desee, a la vez que, entre otras cuestiones que se desarrollarán más adelante, la determinación objetiva de la capacidad y requisitos para contratar con las Administraciones públicas.

5 Que por cierto, la consideración negativa acerca de este elemento, es el criterio fundamental y más manejado por los grupos parlamentarios de Coalición Canaria, Izquierda Unida-Iniciativa por Cataluña y Partido Popular, para interponer enmiendas a la totalidad y solicitar la devolución del Proyecto al Gobierno. 
Por tanto, la consolidación del derecho público de la contratación supone, ni más ni menos, que la existencia de una serie de especialidades que deben desarrollarse en un delicado equilibrio de prerrogativas administrativas y garantías del contratista, para la satisfacción del interés público representado y ejercitado en el contrato.

\section{Principios básicos}

Desde esta perspectiva vamos a desgranar los distintos principios básicos que estructuran la nueva Ley y que aseguran un espacio jurídico y económico común para el Estado.

\section{A) La configuración sustantiva del contrato administrativo}

La nueva Ley de Contratos de las Administraciones Públicas (LCAP) realiza la calificación de contrato administrativo en función de dos elementos, uno subjetivo y el otro objetivo, a la vez que delimita varios ámbitos de aplicación de la Ley, más o menos extensos, en función de la calificación contractual ante la que se esté en cada caso.

De este modo, para que exista un contrato administrativo, debe darse necesariamente la presencia de una Administración pública ${ }^{6}$ y que el objeto de dicho contrato recaiga sobre una determinada serie de materias que, o bien son algunas de las tipificadas expresamente, como son la ejecución de obras, la gestión de servicios públicos y la realización de suministros, los de consultoría y asistencia, de servicios y los de realización de trabajos específicos y concretos no habituales (art. 5.2.a), o teniendo un objeto distinto, poseen una naturaleza administrativa especial; especialidad que viene derivada de su vinculación al giro o tráfico administrativo, de la satisfacción de un fin público o porque así lo declare expresamente una Ley (art. 5.2.b.).

El resto de contratos celebrados por la Administración cuyo objeto se sitúe fuera de los señalados anteriormente, tendrán la consideración de contratos privados y en esa medida, se verán obligados por un ámbito de la LCAP más reducido, como es el conjunto de normas referidas a su preparación y adjudicación, sin perjuicio de las normas administrativas específicas que les sean aplicables.

\footnotetext{
${ }^{6}$ Igualmente, siguiendo el criterio de la Ley 30/1992, de 26 de noviembre, define el concepto de Administración pública, exclusivamente a los efectos de la Ley. Véase el artículo 1 LCAP.
} 
Ahora bien, si quienes contratan son Entidades de Derecho público no incluidas en la definición de Administraciones públicas, quedarán sujetas a las prescripciones de la Ley relativas a la capacidad de las empresas, publicidad, procedimientos de licitación y formas de adjudicación, siempre que se trate de contratos de obras, y de consultoría y asistencia, de servicios y de trabajos específicos y concretos no habituales relacionados con los primeros, que superen una determinada cuantía, y que la financiación principal de dichos contratos proceda directa o indirectamente de las Administraciones públicas (art. 2.1.b.).

Las mismas prescripciones serán aplicables, con independencia de que el contratante sea una Entidad de Derecho privado, ya que se atenderá exclusivamente a la clase de contratos que se suscriban, al objeto sobre el que versen, a su cuantía y a que exista una subvención directa de la Administración de cuantía superior al 50\% de su importe (art. 2.2.).

El resto de contratos, es decir, aquellos calificados legalmente como administrativos, se regirán en cuanto a su preparación, adjudicación, efectos y extinción de manera fundamental por la LCAP, sin perjuicio de la aplicación preferente a los contratos administrativos especiales de sus normas propias, haciendo constar en los pliegos de cláusulas administrativas particulares su carácter de tales, las garantías que el contratista debe prestar, las prerrogativas de la Administración y la competencia de la jurisdicción contencioso-administrativa.

Por tanto, dos parámetros básicos definen los ámbitos de aplicación de la Ley. Uno principal, que es si el contratante es una Administración pública, en cuyo caso todos los contratos, con independencia de su objeto estarán sometidos a los principios, que luego veremos, de publicidad y concurrencia, de igualdad y no discriminación, y otros complementarios como son la clase, cuantía y concurrencia de financiación pública, que condicionan la intensidad de aplicación de la Ley.

Se aprecia por consiguiente en el esquema de la Ley, una correspondencia entre la entidad y consecuencias de distinto orden de la imposición de formas y procedimientos de preparación y adjudicación de los contratos y la clase de actividad pública de contratación, de tal modo que la imposición de esas formas y procedimientos, y en esa medida el control, se aminora a medida que la actividad se produce en la «periferia de lo público», alejándose del centro configurado legalmente por la calificación del contrato.

\section{B) Publicidad y concurrencia}

El principio de publicidad se manifiesta en la LCAP de dos maneras claramente diferenciadas: por una parte, haciendo posible el general conocimiento de las demandas de contratación de las distintas Administra- 
ciones públicas, y en esa medida facilitando la libre concurrencia de cuantos oferentes tengan por conveniente presentar sus licitaciones, y de otra, informando de manera puntual de cuantas adjudicaciones de contratos se producen, mediante la publicación en los distintos Diarios Oficiales, sin perjuicio de la notificación a cada participante en la licitación, y de manera general a través del Registro Público de contratos, de la totalidad de contratos adjudicados y del Registro Oficial de Contratistas de los empresarios clasificados en los distintos grupos de actividad.

De este modo, puede decirse que la publicidad es un principio ínsito del sistema de la LCAP, que posibilita el conocimiento de los procedimientos de contratación puestos en funcionamiento y los sujetos que participan en ellos y consiguientemente actúa como garantía de su correcto funcionamiento.

La concurrencia, sin embargo, aun cuando es un elemento necesario en toda contratación, su graduación está en función de las necesidades que en cada caso tengan las Administraciones públicas, de acuerdo con las determinaciones de la Ley.

En este sentido, la LCAP prevé distintos supuestos de concurrencia de los empresarios. Supuestos que en ningún caso pueden entenderse como de libre elección por parte de la Administración actuante, puesto que la propia Ley establece la obligación, en todo caso, de justificar en el expediente la elección del procedimiento (art. 76.2), pero sobre los que sí existe una elevada discrecionalidad, mayor que en la elección de la forma de adjudicación como luego veremos, que de cualquier manera habrá de ser ejercitada sin vulneración de los principios generales del derecho, y en especial, conforme a los principios de interdicción de la arbitrariedad y de objetividad.

Mientras el procedimiento abierto (art. 74.2) posibilita una concurrencia sin restricciones de ningún tipo, de tal manera que todos los empresarios interesados pueden presentar proposiciones, en el procedimiento restringido (art. 74.3) sólo podrán hacerlo aquellos empresarios que hubiesen sido seleccionados expresamente por la Administración, previa solicitud de los mismos.

Por el contrario, en el procedimiento negociado el contrato es adjudicado al empresario justificadamente elegido por la Administración, previa consulta de sus términos con uno o varios empresarios.

De cualquier modo, es preciso enfatizar que dicho procedimiento sólo podrá ser utilizado en los casos determinados por la Ley para cada clase de contrato (art. 76.1).

\section{C) Igualdad y no discriminación}

La determinación objetiva de criterios y requisitos para contratar con las Administraciones públicas debe ser un componente ineludible del sistema legal de contratación pública. 
Los principios de igualdad y no discriminación, distintas expresiones de una misma idea, son constitucionalizados en el artículo 14 y asumidos expresamente por la LCAP (art. 11.1.), en virtud de lo cual, todos los preceptos de la Ley deben ser interpretados conforme a los mismos.

Los requisitos que establece la Ley para contratar con las Administraciones públicas son, además de la plena disposición de la capacidad de obrar, la acreditación de la solvencia económica, financiera y técnica o profesional o estar inscrito en el Registro Oficial de Contratistas de la Administración Central o en la Administración de las Comunidades Autónomas, en función de la Administración actuante ${ }^{7}$.

La clase y cuantía de los contratos son los criterios determinantes para la exigencia de uno u otro requisito. Si se trata de contratos de obras cuyo presupuesto sea igual o superior a 20 millones de pesetas, o de contratos de consultoría y asistencia, de servicios o de trabajos específicos y concretos no habituales, con presupuesto igual o superior a 10 millones de pesetas, será requisito indispensable la obtención previa de la correspondiente clasificación.

Serán excepción los empresarios extranjeros pertenecientes a Estados miembros de la Comunidad Europea, los cuales acreditarán su solvencia económica y financiera, técnica o profesional, conforme a las determinaciones de la Ley (arts. 16, 17 y 19) y deberán figurar, en su caso, en el Registro profesional o comercial, conforme a las condiciones establecidas en el Estado donde están establecidos.

De cualquier manera, los medios para acreditar la solvencia económica y financiera, la técnica o profesional (arts. 16 a 19), se configuran además como criterios para declarar la clasificación en relación con las características fundamentales de las empresas.

Dada la clase y cuantías de contratos expresadas, como es lógico, la gran mayoría de contratistas deberán obtener la correspondiente clasificación.

Por tanto, la relevancia de los acuerdos de clasificación, en cuanto llaves necesarias para poder concurrir a determinados tipos de contratos, exigen no sólo un desarrollo reglamentario objetivo que asegure la aplicación de los principios que estamos desarrollando, sino sobre todo una actuación administrativa acorde con los mismos, de tal modo que no se produzcan exigencias de clasificación que además de no ser necesarias

7 La Ley crea (art. 35) el Registro Oficial de Contratistas, en el que estarán inscritos todos los empresarios que hayan sido clasificados por la Junta Consultiva y cuyo acceso será público. Dicho Registro y sus correspondientes clasificaciones tendrán carácter estatal y por tanto se extenderán a todas las Administraciones públicas, en la medida en que no existan Registros Oficiales en las correspondientes Comunidades Autónomas. 
para asegurar la capacidad y solvencia del empresario en relación con el contrato a ejecutar, limiten ilegítimamente la concurrencia.

Resulta especialmente positiva, a estos efectos, la incorporación que se produjo en el trámite parlamentario, de las organizaciones empresariales más representativas en los distintos sectores afectados por la contratación administrativa, a las Comisiones clasificadoras que por delegación permanente de la Junta Consultiva de Contratación Administrativa del Ministerio de Economía y Hacienda, entenderán de cuantos expedientes se relacionen con la clasificación de las empresas, produciendo sus acuerdos efectos ante cualquier órgano de contratación de la Administración del Estado y supletoriamente respecto del resto de Administraciones públicas.

Obviamente, en cuanto la capacidad y solvencia de los empresarios es un elemento dinámico, dado que se dictamina en función de factores personales, materiales, económicos y técnicos, susceptibles de cambio y transformación, la clasificación es temporal. La Ley establece dos plazos de duración, cuatro y dos años (art. 30), en función de la valoración de dichos factores a lo largo del tiempo. En ese sentido, la Ley regula también los distintos supuestos de suspensión de las clasificaciones.

A la vez la Ley establece expresamente la prohibición de contratar con la Administración a aquellas personas en las que concurran algunas de las circunstancias que expresamente se determinan (art. 20). Su incumplimiento supondrá la nulidad del contrato.

Por lo que se refiere a las formas de adjudicación o sistemas de selección de contratistas, la LCAP establece tres formas de adjudicación: la subasta, el concurso y el procedimiento negociado, que toma este último el mismo nombre para el procedimiento y para la forma de adjudicación.

Aunque la subasta y el concurso son formas «normales» de adjudicación (art. 76.1) y el procedimiento negociado sólo procederá en los casos en que expresamente se determine en la Ley para cada clase de contrato, es necesario tener en cuenta que, además de la preceptiva y general justificación de la elección de la forma de adjudicación que impone la Ley (art. 76.2), cada tipo de contrato, con la excepción del de obras, establece las preferencias sobre cada forma de adjudicación (en todos ellos se designa el concurso como forma ordinaria, salvo que se den una serie de supuestos que hagan del precio el único factor determinante de la adjudicación), de tal modo que la Administración elegirá la forma de adjudicación, de acuerdo con tales criterios.

La subasta versará necesariamente sobre un tipo expresado en dinero, y la adjudicación se realizará a quien, sin exceder del tipo, oferte el precio más bajo (art. 75.2). 
Parece evidente que la excesiva competencia en las proposiciones y las distintas coyunturas económicas pueden provocar, y de hecho provocan, bajas desproporcionadas o temerarias que es preciso saber identificar.

A este efecto, la Ley remite al desarrollo reglamentario para la determinación de criterios objetivos que permitan su declaración, pero introduce algunos aspectos positivos complemetarios que conviene destacar.

En primer lugar, se requerirá, previamente a la declaración, información a todos los licitadores supuestamente comprendidos en la baja temeraria; en segundo lugar, aunque como derecho supletorio para Administraciones públicas distintas de la del Estado, se dispondrá del asesoramiento técnico del servicio correspondiente que, como parece lógico, deberá derivar en el informe respectivo, y en tercer lugar se prevé la posibilidad de que el órgano de contratación pueda adjudicar a la proposición más baja, pero que pueda ser cumplida a satisfacción de la Administración, o en su defecto a la mejor oferta no incluida en temeridad. Para el caso de que se esté ante el primer supuesto, se exigirá una garantía definitiva por el importe total del contrato adjudicado (art. 84.2).

Ello supone, a nuestro juicio, una combinación razonable entre la ineludible tutela del interés público y el esfuerzo por adaptarse a las circunstancias económicas, en ocasiones locales, que justifican determinadas proposiciones.

Lo que se entiende menos, es que se haya eliminado la preceptividad (art. 32.b. LCE), en la solicitud de informe a la Junta Consultiva de Contratación Administrativa, ante supuestos de bajas desproporcionadas o temerarias.

El concurso, sin embargo, conserva en la LCAP un carácter distinto, por cuanto se valoran a través de él las proposiciones que en conjunto sean más ventajosas, teniendo en cuenta los criterios objetivos que se hayan establecido en los pliegos de cláusulas administrativas particulares, tales como el plazo de ejecución o entrega, la calidad, la rentabilidad, el precio, u otras circunstancias semejantes que configuran globalmente la bondad de la oferta, pero sin atender, por tanto, exclusivamente al precio de las mismas (arts. 75.3 y 87).

En cualquier caso, debe ponerse de manifiesto la necesidad de objetivar la valoración conjunta de las proposiciones. El concurso complejiza la adjudicación, en la medida en que son valorados otros elementos tan importantes como el precio, lo cual no quiere decir que se abra a partir de esta forma de adjudicación una mayor discrecionalidad administrativa, sino un juicio valorativo objetivo más extenso, en cuanto existe un mayor número de elementos a ser valorados. 
Finalmente, la tercera forma de adjudicación es el procedimiento negociado que se configura como una forma excepcional y tasada. En ese sentido, debe aplicarse en los supuestos expresamente previstos en la Ley, desde una interpretación restrictiva en su utilización.

\section{D) Riesgo y ventura}

Aunque el artículo 99 de la LCAP establece que la ejecución de los contratos se realizará a riesgo y ventura del contratista, sin perjuicio de lo aplicable para el contrato de obras en casos de fuerza mayor, vemos que la realidad legislativa no responde a dicho principio.

Originalmente esta expresión quería significar fundamentalmente que la mayor onerosidad sobrevenida del contrato, no autorizaba al contratista a resolver el contrato o simplemente incumplirlo, ni a obtener compensaciones económicas por ello ${ }^{8}$. La extensión que se ha venido realizando de dicho principio a todos los contratos, proviene de la naturaleza del contrato de obras, en cuanto contrato cuyo cumplimiento requiere la obtención de un determinado resultado a un precio alzado.

Sin embargo, junto a este principio se han incorporando otros como la prevalencia del fin sobre el objeto contractual y el mantenimiento del equilibrio financiero del contrato, que han supuesto en la práctica, a través de concepciones como las del contratista-colaborador, la variabilidad del contrato o el equilibrio de la ecuación financiera del contrato, provenientes del contrato de gestión de servicios públicos, la clara relativización de las consecuencias jurídicas del principio de riesgo y ventura consagrado en la Ley.

Además, el contrato de obras, aun cuando es como decimos un contrato de resultado, y en esa medida la prestación debida es la obra terminada y no la actividad necesaria para llevarla a cabo, incluye una regulación de la fuerza mayor, que supone un tratamiento para el contratista más favorable que en la regulación civil.

De este modo, el artículo 144 LCAP reconoce al contratista el derecho a recibir indemnización por los daños y perjuicios que se le hubieren producido en supuestos de incendios causados por la electricidad atmosférica, fenómenos naturales de efectos catastróficos, como maremotos, terremotos, erupciones volcánicas, movimientos del terreno, temporales marítimos, inundaciones u otros semejantes, además de los destrozos ocasionados violentamente en tiempo de guerra, robos tumultuosos o alteraciones graves del orden público.

8 García de Enterría, E. y Fernández Rodríguez, T.R.: Curso de Derecho Administrativo, Tomo I, 6. ${ }^{\mathrm{a}}$ ed., Cívitas, 1993, p. 709. 
Desaparece de la norma la referencia de la Ley anterior a «cualquier otro de efectos análogos a los anteriores, previo acuerdo del Consejo de Ministros» (art. $46 \mathrm{LCE}$ ), que permitía el reconocimiento de otros supuestos de fuerza mayor, lo cual no debe interpretarse en el sentido de considerar el vigente precepto como una lista cerrada de supuestos indemnizables, al margen de la existencia de una auténtica fuerza mayor ${ }^{9}$.

Por tanto, el principio de riesgo y ventura, como veremos a continuación, justifica algunas especialidades en el contrato administrativo que suponen situaciones gravosas para el contratista, pero desde luego queda sensiblemente relativizado por la aplicación de otros principios más definidores del derecho público de la contratación.

\section{E) Equivalente económico}

No es posible asumir en toda su extensión la problemática derivada del pretendido equilibrio de las contraprestaciones en el contrato administrativo.

Sin embargo, vamos a detenernos en aquellas cuestiones que, a nuestro juicio, son fundamentales en relación con esta cuestión.

Debemos comenzar señalando que los elementos aplicables por la Teoría general del Derecho a los contratos no pueden ser de aplicación a aquellos que son suscritos con las Administraciones públicas y están sujetos al Derecho público. Principalmente porque la Administración tiene encomendada constitucionalmente la satisfacción de los intereses generales y porque todos los ciudadanos, incluidos los contratistas, deben ser tratados conforme al principio de igualdad de cargas públicas ${ }^{10}$. Por tanto, la medida de equilibrio entre las contraprestaciones será la medida en que la actividad contratada y desarrollada es remunerada con su equivalente económico. Sin embargo, es difícil aceptar la existencia de una sola solución justa en la determinación del precio, supuesta la diversidad de técnicas, pericias y formas de acometer la actividad. Por eso el equilibrio tendrá un margen derivado y justificado en la capacidad competetitiva de los contratistas sin asumir pérdidas.

La LCAP, de la misma manera que señalaba la LCE, establece que los contratos tendrán un precio cierto de acuerdo con lo convenido, «en función de la prestación realmente efectuada», exhortando a los órganos de contratación para que cuiden «de que el precio de los contratos sea el

9 García de Enterría, E. y Fernández Rodríguez, T.R.: Curso de Derecho..., op. cit., pp. 721-2.

10 Ariño ORTiZ, G.: La reforma de la Ley..., op. cit., p. 100. 
adecuado al mercado» (art. 14.1). Así, el legislador sigue estableciendo como medida del equilibrio entre bienes y precio, la adecuación a la prestación real que se efectúe.

Ahora bien, el cumplimiento con el equilibrio en la ecuación contractual no se plantea exclusivamente en el momento de determinación del precio, ni incluso en el correspondiente a la formalización del contrato, sino que dicho equilibrio debe perdurar hasta su extinción.

Evidentemente, todo lo que no sea equilibrio de las contraprestaciones, en el momento de su determinación y a lo largo de su desarrollo, supondrá un enriquecimiento injusto de la Administración ${ }^{11}$.

Los supuestos que ha ido construyendo la jurisprudencia del Consejo de Estado francés, en los que se debe producir un reequilibrio de la ecuación financiera del contrato, constituyen ya referencias clásicas en la explicación y justificación del equivalente económico.

$\mathrm{Ni}$ el denominado factum principis, ni el riesgo imprevisible han sido acogidos legislativamente ${ }^{12}$, sin embargo pueden entenderse reconducibles a la fórmula de revisión de precios, donde sí se produce una alteración sustancial respecto a la legislación anterior.

En primer lugar, hay que señalar que el sistema de revisión de precios deja de ser transitorio, incorporándose a la Ley como factor permanente de reequilibrio contractual. En segundo lugar, deja de ser un sistema excepcional, ya que, como es sabido, en la legislación anterior las cláusulas de revisión se aplicaban ex contractu, mientras que en la actual se incorpora el derecho ex lege de revisión de todos los contratos, con la excepción de los de trabajos específicos y concretos no habituales. En tercer lugar, este derecho debe entenderse general, en cuanto se establece sin predeterminaciones respecto al origen del desequilibrio contractual y en cuanto prevé el deber de detallar en el pliego de cláusulas administrativas particulares la fórmula o sistema de revisión que sea aplicable. Deber que sólo será excusable si, mediante resolución motivada, se establece en el mismo pliego la improcedencia de la revisión (art. 104.3).

En lo que menos se ha alterado el sistema de revisión de precios es en la cuantía y alcance de la revisión.

11 En este sentido Vid. AriÑo OrTiz, G.: Teoría del equivalente económico en los contratos administrativos, ENAP, Madrid, 1968, p. 303. Rebollo Puig, M.: El enriquecimiento injusto de la Administración pública, Marcial Pons, 1995, pp. 121 y ss. Cosculluela Montaner, L.: «Consideración sobre el enriquecimiento injusto en el Derecho Administrativo», RAP, núm. 84, pp. 192 y ss.

12 Salvo por lo recogido en relación con las concesiones de servicios públicos, en el artículo 127.2 del Reglamento de Servicios de las Corporaciones Locales. 
Como veíamos, el principio de riesgo y ventura del empresario consagrado en la Ley se ve hasta cierto punto arrumbado por la consideración y efectos del equivalente económico de las prestaciones. Sin embargo, no se han eliminado de esta Ley todas las influencias de aquel principio.

El fundamento teórico sobre el que se partió para aceptar la revisión de precios en 1964, fue la consideración de la doctrina del riesgo imprevisible, es decir la procedencia de que el empresario asuma, al menos parcialmente, en una especie de reparto, la elevación de los precios ${ }^{13}$.

Este fundamento pervive en la vigente Ley, en la medida en que subsisten algunos límites a la extensión de las fórmulas revisoras.

Así, subsiste el límite de obra realizada y se incorpora el complementario de tiempo de ejecución, de tal modo que la revisión tendrá lugar cuando, al menos, se hubiese ejecutado el $20 \%$ del importe del contrato y hayan transcurrido seis meses desde su adjudicación (art. 104.1). Desaparece la imposibilidad de revisión por el hecho de que el contratista hubiese incurrido en mora; eso sí, la revisión se referirá a los índices que procedieran en la realización de la prestación en plazo.

Permanece también el límite de conceptos no revisables, en cuanto son excluidos de tal revisión los gastos que deben mantenerse invariables, representados en un $15 \%$ del presupuesto (art. 105.2).

Pero sin embargo, se elimina el nivel mínimo de variación de los precios, por encima del cual se debía producir la revisión, lo cual tiene un doble efecto, tanto respecto de los supuestos en que se producían variaciones por debajo del mínimo y no procedía la revisión, como de aquellos que procediendo la revisión por superarlo, dicha revisión no incluía ese mínimo y se aplicaba a partir de él (art. LCE).

Puede decirse, por tanto, que el equivalente económico es un principio que inspira el contrato administrativo, y que lo inspira en la regulación que la vigente Ley se realiza, a pesar de la existencia de factores que atienden a otras concepciones, en cierta medida contradictorias, pero todavía incorporadas a Ley vigente.

\section{F) Supremacía de la Administración}

La Administración concurre en las relaciones jurídico-administrativas como potentior persona, investida de una serie de privilegios y prerrogativas que son consecuencia de la naturaleza pública de los intereses que tutela. En esa medida, también está sometida a una serie de formas y procedimientos que configuran el patrimonio garantista del ciudadano.

13 Ariño Ortiz, G.: La Reforma de la Ley..., op. cit., p. 131. 
No puede hablarse, por consiguiente, de una situación de igualdad entre las partes de un contrato administrativo ${ }^{14}$, sino de la composición de una situación de equilibrio, desde las distintas y desiguales posiciones que ostentan y representan las partes en un contrato administrativo.

Si las potestades de dirección e inspección, sancionadora y de interpretación del contrato, se atribuyen a la Administración como instrumentos para mejor desarrollar su tutela en defensa de lo pactado, y en consecuencia poder actuar sin la intervención de los Tribunales, es decir ejercitando su autotutela declarativa y ejecutiva, ninguna de ellas permite a la Administración separarse de lo pactado o convenido. Lo que suponen, simple y llanamente, es aplicar a la institución contractual las cualidades incorporadas por el ordenamiento jurídico a las Administraciones públicas.

Distinta por sus consecuencias en la administración del contrato es el ius variandi.

El órgano de contratación sigue teniendo la posibilidad de modificar el contrato, siempre que las modificaciones estén basadas en razones de interés público, sean debidas a necesidades nuevas o causas imprevistas y se justifique adecuadamente en el expediente.

Lógicamente, las consecuencias derivadas del ejercicio del ius variandi deberán ser adecuadamente compensadas por la administración, tanto en lo referido a los incrementos de costes, como en los daños que pudieran ocasionarse al contratista. Los efectos de las modificaciones contractuales pueden ser diversos y son regulados en la Ley para cada tipo de contrato.

La suspensión de los contratos puede ser considerada, por otra parte, como una extensión de la modificación contractual. Cuando la Administración acordare la suspensión del contrato, siempre que ésta no sea superior a seis meses y constituya causa de resolución, o tuviera lugar por decisión del contratista ante la falta de pago de la Administración, se levantará un acta en la que se consignarán las circunstancias que la han motivado y la situación en que está la ejecución del contrato, y la Administración abonará al contratista los daños y perjuicios efectivamente sufridos por éste (art. 103).

Sin embargo, puede decirse, sin profundizar en este momento sobre todo ello, que se ha producido un notable avance en esa idea de reconstruir

\footnotetext{
14 Martín Retortillo, S. en «La institución contractual en el Derecho Administrativo: en torno a la igualdad de las partes», RAP, núm. 29, p. 101, señala que más que la igualdad, lo que importa es la fuerza que posea la voluntad de cada parte para establecer la correspondiente relación jurídica.
} 
el equilibrio entre las partes, modificando las condiciones que permitían escribir en el pasado, sobre un cierto privilegio administrativo de incumplir $^{15}$, en relación a la diferencia de efectos del incumplimiento del contratista, que el artículo 159 RCE «refería a cualquier cláusula contenida en el contrato», a efectos de autorizar la resolución del contrato, respecto del incumplimiento de la Administración, que sólo posibilitaba aquélla «en los casos previstos en esta Ley» (art. 53 LCE). Esa postura tenía su correlativa proyección en el tratamiento que se daba a la demora en el pago del precio por parte de la Administración, o en el plazo de la suspensión temporal sin constituir causa de resolución, entre otros. En ambos casos, por seguir con los mismos ejemplos, se ha producido un avance en el reequilibrio a que antes aludíamos, y que denota un cambio de perspectiva. Cambio que también alcanza a la determinación de las causas de resolución.

\section{G) Contractus lex}

Es bastante claro ya para este momento, que muchas de las consecuencias que se derivan de la consideración del acuerdo de voluntad de las partes, como primera ley para las mismas, han quedado desvirtuadas para el contrato administrativo.

Sin embargo, resta señalar someramente algunas reflexiones en torno a la obligatoriedad de cumplir por parte de los contratantes, y más específicamente por la Administración los contratos viciados de invalidez.

El artículo 4 LCAP establece que la Administración podrá concertar cuantos contratos, pactos y condiciones tenga por conveniente, siempre que no sean contrarios al interés público, al ordenamiento jurídico o a los principios de buena administración, y añade que deberá cumplirlos a tenor de los mismos, sin perjuicio de las prerrogativas establecidas por la legislación básica en favor de aquélla.

No parece que exista duda respecto de la obligatoriedad que el mencionado precepto impone a la Administración, para el cumplimiento de contratos que pudieran adolecer de algún vicio de invalidez. No obstante, no parece lógico mantener la ejecución de un contrato sobre el que pese alguna irregularidad invalidante, especialmente si existen terceros, que pudieran resultar perjudicados.

En cualquier caso, si la declaración administrativa de nulidad de un contrato produjese un grave trastorno al servicio público, queda la posibilidad de que se disponga en el mismo acuerdo la continuación de los

15 García de Enterría, E. y Fernández Rodríguez, T.R.: Curso de Derecho..., op. cit., pp. 732 y ss. 
efectos del contrato bajo sus mismas cláusulas, hasta que se adopten urgentemente las medidas necesarias para evitar el perjuicio (art. 66.3).

Por tanto, la Administración no podrá apartarse libérrimamente de la vinculación contractual, pero sí podrá, más bien deberá a nuestro juicio, ejercitar sus prerrogativas.

En ese sentido, la declaración de nulidad de los contratos por causas de nulidad y anulabilidad, podrá ser acordada por el órgano de contratación, de oficio o a instancia de los interesados, previo dictamen favorable del Consejo de Estado u órgano consultivo equivalente de la Comunidad Autónoma respectiva (art. 65.1 LCAP), de acuerdo con los requisitos y plazos establecidos en la LRJPAC.

Asimismo, la suspensión de la ejecución de los actos de los órganos de contratación se llevará a cabo de acuerdo con la citada Ley y con la LJCA.

La nueva regulación de la suspensión incluida en la Ley 30/1992, de 26 de noviembre, amplía expresamente la capacidad de la Administración para suspender la ejecución de un acto administrativo, sobre el que se haya iniciado un procedimiento de revisión de oficio ${ }^{16}$, siempre que dicha ejecución pudiera causar perjuicios de imposible o difícil reparación, y mantiene, con una ordenación más completa, la regulación referida a suspensiones de ejecución de actos recurridos.

Todo ello, claro está sin perjuicio de las indemnizaciones que la parte culpable deba satisfacer a la contraria, como consecuencia de los daños y perjuicios sufridos.

En cualquier caso, por tanto, la Administración estará obligada al cumplimiento del contrato o al ejercicio de sus prerrogativas, tanto en referido a las declaraciones de nulidad, como en las suspensiones de ejecución.

\section{H) La forma de contrato}

El artículo 56 LCAP prohíbe a la Administración contratar verbalmente, salvo que el contrato tenga carácter de emergencia. Es más, la Ley prohíbe también iniciar la ejecución sin que se haya procedido a la previa formalización, salvo que se esté ante tramitaciones urgentes o de emergencia (art. 55.4). Los contratos se formalizarán en documento

16 Aunque a decir verdad, bajo la vigencia de la LPA, ya se manifestó el Consejo de Estado, a través de su Dictamen de 12 de julio de 1962, en un sentido favorable a la aplicación analógica del artículo 116 LPA, en el que se preveía la suspensión de los actos administrativos recurridos. 
administrativo, dentro del plazo de treinta días, plazo de derecho supletorio para las CCAA, siendo suficiente dicho documento para el acceso a cualquier registro público ${ }^{17}$. No obstante, podrá elevarse a escritura pública cuando lo solicite el contratista, siendo a su costa los gastos que se deriven de su otorgamiento (art. 55.1).

De cualquier forma hay que tener en cuenta que la formalización escrita no tiene carácter constitutivo ${ }^{18}$. La perfección del contrato se realiza mediante la adjudicación por el órgano administrativo correspondiente, cualquiera que sea el procedimiento o la forma de adjudicación que se hayan utilizado (art. 54). Por ello, cuando no pudiese formalizarse el contrato, dentro del plazo establecido, la Administración podrá acordar su resolución, con la incautación por incumplimiento, de la garantía provisional y la indemnización, en su caso, de los daños y perjuicios ocasionados. Los mismos efectos causará el incumplimiento de la Administración (art. 55.3).

Este conjunto de principios articulan y explican el funcionamiento modulado de la institución contractual, conforme a las normas del ordenamiento jurídico-administrativo.

Desde ellos se entiende la coexistencia del acuerdo contractual y su correspondiente administración, con intereses públicos y privilegios y prerrogativas administrativas, en una atmósfera general de reconstrucción y garantía del equilibrio de partes y prestaciones.

17 En este sentido se ha manifestado la doctrina, Vid. ARIÑo OrTIZ, G.: La reforma de la Ley..., op. cit., pp. 79 a 82.

18 Cfr. García de Enterría, E. y Fernández Rodríguez, T.R.: Curso de Derecho Administrativo, Tomo I, Cívitas, 1995, p. 688. 